COSTA, N.L. et al. Produção de forragem, composição química e morfogênese de Brachiaria humidicola cv. Tupi em diferentes idades de corte. PUBVET, Londrina, V. 5, N. 8, Ed. 155, Art. 1044, 2011.

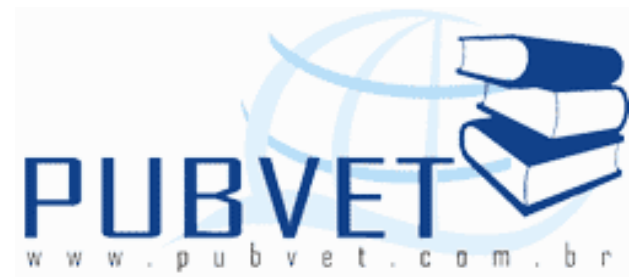

PUBVET, Publicações em Medicina Veterinária e Zootecnia.

\title{
Produção de forragem, composição química e morfogênese de Brachiaria humidicola cv. Tupi em diferentes idades de corte
}

Newton de Lucena Costa ${ }^{1}$, Valdinei Tadeu Paulino ${ }^{2}$, Anibal de Moraes ${ }^{3}$, João Avelar Magalhães ${ }^{4}$

${ }^{1}$ Eng. Agr., M.Sc., Embrapa Roraima, Doutorando em Agronomia/Produção Vegetal, UFPR, Curitiba, Paraná. E-mail: newton@cpafrr.embrapa.br

${ }^{2}$ Eng. Agr., D.Sc., Instituto de Zootecnia, Nova Odessa, São Paulo. E-mail: paulino@iz.sp.gov.br

${ }^{3}$ Eng. Agr., D.Sc., Professor Associado II, UFPR, Curitiba, Paraná. E-mail: anibalmr@ufpr.br

${ }^{4}$ Med. Vet., D.Sc., Embrapa Meio Norte, Parnaíba, Piauí. E-mail: avelar@cpamn.embrapa.br

\section{Resumo}

O efeito da idade da planta (14, 21, 28, 35 e 42 dias) sobre a produção e composição química da forragem e características morfogênicas e estruturais de Brachiaria humidicola cv. Tupi foi avaliado em condições de casa-de-vegetação. O aumento da idade das plantas resultou em maiores rendimentos de forragem e vigor de rebrota, contudo implicou em decréscimos significativos dos teores de nitrogênio, fósforo, magnésio e potássio, enquanto que os de cálcio não foram afetados. Para todas as idades de cortes, os teores de nitrogênio ficaram abaixo do seu nível crítico. 
COSTA, N.L. et al. Produção de forragem, composição química e morfogênese de Brachiaria humidicola cv. Tupi em diferentes idades de corte. PUBVET, Londrina, V. 5, N. 8, Ed. 155, Art. $1044,2011$.

O tamanho médio de folhas e suas taxas de senescência foram diretamente proporcionais às idades das plantas, ocorrendo o inverso quanto à taxa de aparecimento de folhas. As maiores taxas de aparecimento e de expansão foliar e o tamanho médio de folhas foram obtidos, respectivamente, aos 41,$1 ; 31,3$ e 38,9 dias. A idade de corte mais adequada para pastagens de B. humidicola cv. Tupi, visando a conciliar produção, vigor de rebrota e qualidade da forragem, situa-se entre 28 e 42 dias.

Palavras-chave: composição química, folhas, idade da planta, matéria seca, morfogênese

\title{
Forage yield, chemical composition and morphogenesis of Brachiaria humidicola cv. Tupi at differents plant age
}

\begin{abstract}
The effects of plant age $(14,21,28,35$ and 42 days) on dry matter (DM) yield, chemical composition and morphogenetic and structural characteristics of Brachiaria humidicola cv. Tupi, was evaluated under greenhouse with natural conditions of light and temperature. DM yields and regrowth, leaf blade lenght, and lifespan rate increased consistently with growth stage, however the nitrogen, phosphorus, magnesium, and potassium contents decreased as plant age, while calcium contents were not affected by plant age. For all plant ages, nitrogen contents were lower than its critic level. Maximum leaf appearance and elongation rates, and blade lenght were obtained with cutting at $41.1 ; 31.3$ and 38.9 days, respectively. These data suggest that cutting at 28 to 42 days were optimal for obtain maximum yields and regrowth of rich forage and pasture persistence.
\end{abstract}

Keywords: chemical composition, dry matter, leaves, morphogenesis, plant age 
COSTA, N.L. et al. Produção de forragem, composição química e morfogênese de Brachiaria humidicola cv. Tupi em diferentes idades de corte. PUBVET, Londrina, V. 5, N. 8, Ed. 155, Art. 1044, 2011.

\section{Introdução}

Em Rondônia, as pastagens cultivadas representam a fonte mais econômica para alimentação dos rebanhos. No entanto, face às oscilações climáticas, a produção de forragem durante o ano apresenta flutuações estacionais, ou seja, abundância no período chuvoso (outubro a maio) e déficit no período seco (junho a setembro), o que afeta negativamente os índices de produtividade animal (COSTA et al., 1988). A utilização de práticas de manejo adequadas é uma das alternativas para reduzir os efeitos da estacionalidade na produção de forragem.

O estádio de crescimento em que a planta é colhida afeta diretamente o rendimento, composição química, capacidade de rebrota e persistência. Em geral, cortes ou pastejos menos freqüentes fornecem maiores produções de forragem, porém, concomitantemente, ocorrem decréscimos acentuados em sua composição química, com maior deposição de material fibroso, decréscimo na relação folha/colmo e, consequentemente, menor consumo pelos animais (COSTA; OLIVEIRA, 1994; COSTA et al., 1997). Logo, deve-se procurar o ponto de equilíbrio entre produção e qualidade da forragem, visando assegurar os requerimentos nutricionais dos animais e garantindo, simultaneamente, a persistência e a produtividade das pastagens.

A produtividade das gramíneas forrageiras decorre da contínua emissão de folhas e perfilhos, processo importante para a restauração da área foliar após corte ou pastejo e que assegura a sua perenidade. Os processos de formação e desenvolvimento de folhas são fundamentais para o crescimento vegetal, considerando-se a sua importância para a fotossíntese, ponto inicial para a formação de novos tecidos (GOMIDE, 1997; LEMAIRE, 2001). A morfogênese de uma gramínea durante seu crescimento vegetativo pode ser descrita por três variáveis: a taxa de aparecimento, a taxa de alongamento e a duração de vida das folhas, as quais, apesar de sua natureza genética, são fortemente influenciadas pelas condições ambientais (temperatura, luz, água e fertilidade do solo) e práticas de manejo. As interações entre estas variáveis determinam as características estruturais: número de folhas vivas/perfilho (NFV), tamanho final de folhas (TFF) e densidade de perfilhos, as quais irão determinar o índice de área foliar (IAF), ou seja, o aparato utilizado para a interceptação da radiação pelo dossel da pastagem. 
COSTA, N.L. et al. Produção de forragem, composição química e morfogênese de Brachiaria humidicola cv. Tupi em diferentes idades de corte. PUBVET, Londrina, V. 5, N. 8, Ed. 155, Art. 1044, 2011.

O NFV é decorrente da taxa de aparecimento e a duração de vida das folhas, sendo determinado geneticamente, enquanto que a taxa de alongamento foliar condiciona o TFF (CHAPMAN; LEMAIRE, 1993). O conhecimento das características morfogênicas e estruturais proporciona uma visualização da curva estacional de produção de forragem e uma estimativa de sua qualidade (GOMIDE, 1994), além de permitir a proposição de práticas de manejo específicas para cada gramínea forrageira (GOMIDE; GOMIDE, 2000; LEMAIRE, 2001).

Neste trabalho foram avaliados os efeitos da idade das plantas sobre a produção de forragem, vigor de rebrota, composição química e características morfogênicas de Brachiaria humdicola cv. Tupi.

\section{Material e Métodos}

O ensaio foi conduzido em casa-de-vegetação, utilizando-se um Latossolo Amarelo, textura argilosa, o qual apresentava as seguintes características químicas: $\mathrm{pH}=5,1 ; \mathrm{Al}=1,1 \mathrm{cmol} / \mathrm{dm}^{3} ; \mathrm{Ca}+\mathrm{Mg}=2,3 \mathrm{cmol} / \mathrm{dm}^{3} ; \mathrm{P}=3 \mathrm{mg} / \mathrm{kg}$ e $\mathrm{K}=87 \mathrm{mg} / \mathrm{kg}$. O solo foi coletado na camada arável $(0$ a $20 \mathrm{~cm}$ ), destorroado e passado em peneira com malha de $6 \mathrm{~mm}$ e posto para secar ao ar. O delineamento experimental foi em blocos casualizados com três repetições. Os tratamentos consistiram de cinco idades de corte (14, 21, 28, 35 e 42 dias). A adubação de estabelecimento constou da aplicação de 40 e $44 \mathrm{mg} / \mathrm{dm}^{3}$ de fósforo e nitrogênio, sob a forma de uréia e superfosfato triplo, respectivamente. Cada unidade experimental constou de um vaso com capacidade para $4,0 \mathrm{dm}^{3}$ de solo seco. Dez dias após a emergência das plantas executou-se o desbaste, deixando-se duas plantas/vaso. O controle hídrico foi realizado diariamente através da pesagem dos vasos, mantendo-se o solo em $80 \%$ de sua capacidade de campo.

O corte de uniformização foi realizado 35 dias após o desbaste das plantas a uma altura de $10 \mathrm{~cm}$ acima do solo. Os parâmetros avaliados foram rendimento de matéria seca $(M S)$, teores de nitrogênio $(N)$, fósforo $(P)$, cálcio $(C a)$, magnésio $(\mathrm{Mg})$ e potássio (K), nível crítico de $\mathrm{N}(\mathrm{NCN})$, índice de nutrição nitrogenada (INN), taxa de aparecimento de folhas (TAF), taxa de expansão foliar (TEF) e tamanho médio de folhas (TMF). A TEF e a TAF foram calculadas dividindo-se o comprimento acumulado de folhas e o número total de folhas no afilho, respectivamente, pelo 
COSTA, N.L. et al. Produção de forragem, composição química e morfogênese de Brachiaria humidicola cv. Tupi em diferentes idades de corte. PUBVET, Londrina, V. 5, N. 8, Ed. 155, Art. 1044, 2011.

período de rebrota. O TMF foi determinado pela divisão do alongamento foliar total do afilho pelo seu número de folhas. A taxa de senescência foliar (TSF) foi obtida dividindo-se o comprimento da folha que se apresentava de coloração amarelada ou necrosada pela idade da planta ao corte. O NCN foi determinado pela metodologia proposta por Lemaire e Salette (1984), para gramíneas $C_{4}$, através da fórmula: $\mathrm{NCN}=3,6 \cdot \mathrm{MS}^{(-0,34)}$, o qual estima a curva de diluição do $\mathrm{N}$, em função do acúmulo de MS. O INN foi obtido pela razão entre o teor de $\mathrm{N}$ na MS e o NCN, sendo considerado satisfatório quando o resultado é igual a 1,0 (LEMAIRE; GASTAL, 1997). O vigor de rebrota foi avaliado através da produção de MS aos 21 dias após o corte à idade do primeiro corte.

\section{Resultados e Discussão}

Os rendimentos de MS foram significativamente $(P<0,05)$ incrementados com a idade das plantas, sendo a relação quadrática e descrita pela equação: $Y=$ $4,6801+0,61913 X-0,007912 X^{2}\left(R^{2}=0,9422\right)$ e o valor máximo estimado aos 39,1 dias de rebrota (Tabela 1 ). Resultados semelhantes foram relatados por Costa et al. (2004a) avaliando diversos genótipos de B. brizantha, em diferentes idades de cortes. $O$ vigor de rebrota foi significativamente $(P<0,05)$ afetado pela idade da planta, sendo as maiores produções de MS obtidas com cortes aos 28, 35 e 42 dias, as quais não diferiram entre si $(P>0,05)$. $O$ efeito da idade das plantas ajustou-se ao modelo quadrático de regressão, descrito pela equação $Y=-3,25+$ $0,43173 X-0,005466 X^{2}\left(R^{2}=0,96\right)$, sendo a produção máxima de MS da rebrota estimada em 39,5 dias. Da mesma forma, Costa et al. (2004b), em condições de campo, observaram que o máximo vigor de rebrota de $B$. humidicola ocorreu no período entre 28 e 35 dias após o corte das plantas. 
COSTA, N.L. et al. Produção de forragem, composição química e morfogênese de Brachiaria humidicola cv. Tupi em diferentes idades de corte. PUBVET, Londrina, V. 5, N. 8, Ed. 155, Art. 1044, 2011.

Tabela 1. Rendimento de matéria seca (MS), vigor de rebrota (VR), taxa de aparecimento de fol has (TAF), taxa de expansão foliar (TEF), tamanho médio de folhas (TMF) e taxa de senescência foliar TSF) de Brachiaria humidicola cv. Tupi, em função da idade das plantas.

\begin{tabular}{ccccccc}
\hline $\begin{array}{c}\text { Idade } \\
\text { (dias) }\end{array}$ & $\begin{array}{c}\text { MS } \\
\text { (g/vaso) }\end{array}$ & $\begin{array}{c}\text { VR } \\
\text { (g MS/21 dias) }\end{array}$ & $\begin{array}{c}\text { TAF } \\
\text { (folha/dia/perfilho) }\end{array}$ & $\begin{array}{c}\text { TEF } \\
\text { (cm/dia/perfilho) }\end{array}$ & $\begin{array}{c}\text { TMF } \\
(\mathrm{cm})\end{array}$ & $\begin{array}{c}\text { TSF } \\
\text { (cm/dia/perfilho) }\end{array}$ \\
\hline 14 & $2,95 \mathrm{~d}$ & $1,81 \mathrm{c}$ & $0,214 \mathrm{a}$ & $2,13 \mathrm{a}$ & $9,8 \mathrm{c}$ & -- \\
21 & $4,58 \mathrm{c}$ & $3,19 \mathrm{~b}$ & $0,190 \mathrm{~b}$ & $2,45 \mathrm{a}$ & $11,2 \mathrm{~b}$ & -- \\
28 & $7,75 \mathrm{~b}$ & $4,61 \mathrm{a}$ & $0,178 \mathrm{c}$ & $2,52 \mathrm{a}$ & $13,1 \mathrm{a}$ & $0,074 \mathrm{~b}$ \\
35 & $8,53 \mathrm{ab}$ & $5,28 \mathrm{a}$ & $0,171 \mathrm{~cd}$ & $2,60 \mathrm{a}$ & $13,8 \mathrm{a}$ & $0,087 \mathrm{a}$ \\
42 & $9,46 \mathrm{a}$ & $5,16 \mathrm{a}$ & $0,166 \mathrm{~d}$ & $2,40 \mathrm{a}$ & $14,0 \mathrm{a}$ & $0,098 \mathrm{a}$ \\
\hline
\end{tabular}

- Médias seguidas de mesma letra não diferem entre si ( $(\mathrm{P}>0.05)$ pelo teste de Tukey

As relações entre idade das plantas e a TAF, TEF e TMF foram ajustadas ao modelo quadrático de regressão, sendo definidas, respectivamente, pelas equações: $Y=0,27-0,005153089 X+0,0000626826 X^{2}\left(R^{2}=0,98\right) ; Y=1,11+$ $0,093937 X-0,001501429 X^{2}\left(R^{2}=0,96\right)$ e $Y=4,38+0,4510157 X$ $0,005797727 X^{2}\left(R^{2}=0,97\right)$. Os valores máximos para a TAF, TEF e o TMF foram obtidos aos 41,$1 ; 31,3$ e 38,9 dias, respectivamente (Tabela 1). Em pastagens de B. humidicola e B. dictyoneura, Costa et al. (2004a) constataram maiores TEF no período compreendido entre 21 e 28 dias de rebrota. As TAF e TEF obtidas neste trabalho, independentemente das idades das plantas, foram superiores às reportados por Difante et al. (2005), avaliando B. brizantha cv. Marandu, em condições de campo, sob diferentes intervalos entre cortes, que estimaram valores médios de 0,083 folhas/perfilho/dia e 1,61 cm/dia/perfilho. Contudo, o TMF foi inferior ao reportado por Costa et al. (2007) para B. humidicola submetida a diferentes níveis de nitrogênio $(17,4 \mathrm{~cm})$

A TEF, em decorrência de sua alta correlação com a produção de biomassa, tem sido utilizada como um dos critérios para a seleção de germoplasma forrageiro em trabalhos de melhoramento genético (HORST et al., 1978). No presente trabalho, a correlação entre rendimento de MS e TEF foi positiva e não significativa $(r=0,7435 ; p=0,1497)$, enquanto que com a TAF a correlação foi negativa e significativa ( $r=-0,9673 ; p=0,0071$ ). A TEF e a TAF explicaram em 55,2 e 93,6\%, respectivamente, os incrementos verificados nos rendimentos de MS da gramínea, em função da idade das plantas. A TAF é a característica morfogênica que merece maior destaque, uma vez que afeta diretamente as três características estruturais do relvado: tamanho da folha, densidade populacional de perfilhos e número de 
COSTA, N.L. et al. Produção de forragem, composição química e morfogênese de Brachiaria humidicola cv. Tupi em diferentes idades de corte. PUBVET, Londrina, V. 5, N. 8, Ed. 155, Art. 1044, 2011.

folhas/perfilho (LEMAIRE et al., 1989; CHAPMAN; LEMAIRE, 1993). A correlação entre TAF e TEF foi negativa e significativa ( $r=-0,8113 ; p=0,0955)$. Segundo Zarrough et al. (1984), as TAF e TEF apresentam uma correlação negativa, indicando que quanto maior a TAF, menor será o tempo disponível para o alongamento. Grant et al. (1981) observaram que a TEF foi positivamente correlacionada com a quantidade de folhas verdes remanescentes no perfilho após a desfolhação, sendo o tamanho do perfilho o responsável pela longa duração da TEF.

A TSF foi afetada $(P<0,05)$ pela idade das plantas; 0 processo de senescência só ocorreu a partir dos 28 dias de idade, sendo as maiores taxas verificadas aos 42 e 35 dias de idade (Tabela 1). Os valores registrados neste trabalho foram inferiores aos reportados por Difante et al. (2005) para B. brizantha cv. Marandu, que obtiveram TSF de 0,102; 0,109 e 0,170 cm/dia/perfilho, respectivamente para cortes em plantas com três, quatro e cinco folhas surgidas, as quais apresentaram uma duração média de vida de 65,1 dias. Gonçalves (2002) estimou em 34,$4 ; 43,1 ; 45,5$ e 48,4 dias, a duração de vida da folha de $B$. brizanta $\mathrm{cv}$. Marandu, respectivamente para pastagens manejadas a 10,20, 30 e $40 \mathrm{~cm}$ de altura. A senescência foliar reduz a quantidade de forragem de boa qualidade, pois as porções verdes da planta são as mais nutritivas para a dieta animal, sendo causada pela competição por metabólitos e nutrientes entre as folhas velhas e as jovens em crescimento (LEITE et al., 1998). A senescência é um processo natural que caracteriza a última fase de desenvolvimento de uma folha, iniciada após sua completa expansão, cuja intensidade se acentua progressivamente com o aumento da área foliar, em decorrência do sombreamento das folhas inseridas na porção inferior do colmo (NABINGER, 1997). Apesar do efeito negativo sobre a qualidade da forragem, a senescência representa um importante processo fisiológico no fluxo de tecidos da gramínea, pois cerca de $50 \%$ do carbono e $80 \%$ do nitrogênio são reciclados das folhas senescentes e utilizados pela planta para a produção de novos tecidos foliares (CARRÈRE et al., 1997; LEMAIRE; AGNUSDEI, 2000).

Os teores de $\mathrm{Ca}$ não foram afetados $(\mathrm{P}>0,05)$ pela idade das plantas, enquanto que os de $\mathrm{N}, \mathrm{P}, \mathrm{Mg}$ e $\mathrm{K}$ decresceram com o avanço do estádio de crescimento da gramínea. $O$ efeito da idade das plantas foi linear e negativo, sendo 
COSTA, N.L. et al. Produção de forragem, composição química e morfogênese de Brachiaria humidicola cv. Tupi em diferentes idades de corte. PUBVET, Londrina, V. 5, N. 8, Ed. 155, Art. 1044, 2011.

descrito pelas equações $Y=27,11-0,3539 X\left(r^{2}=0,98\right) ; Y=1,69-0,005285 X$ $\left(r^{2}=0,97\right) ; Y=5,12-0,01014 \times\left(r^{2}=0,98\right) ; Y=4,20-0,03486 \times\left(r^{2}=0,96\right)$ e $Y=19,32-0,117 \times\left(r^{2}=0,94\right)$, respectivamente para os teores de $\mathrm{N}, \mathrm{P}, \mathrm{Ca}, \mathrm{Mg} \mathrm{e}$ $\mathrm{K}$. Em geral, as maiores concentrações foram registradas com cortes entre 14 e 28 dias (Tabela 2). Os teores obtidos neste trabalho são semelhantes ou superiores aos relatados por Costa et al. (2004b) para diversos genótipos de Brachiaria, colhidos em diferentes idades de cortes. Considerando-se que teores de proteína bruta inferiores a 7\% são limitantes à produção animal, por implicarem em menor consumo voluntário, redução na digestibilidade da forragem e balanço nitrogenado negativo, observa-se que a gramínea atenderia, satisfatoriamente, aos requerimentos mínimos dos ruminantes em cortes com plantas com até 42 dias de idade. A relação entre $\mathrm{MS}$ e teor de $\mathrm{N}$ foi ajustada ao modelo exponencial de regressão $\left(Y=28,6016 . e^{(-0,0779 x)} ; R^{2}=0,8321\right)$, evidenciando o efeito de diluição de seus teores, em função do maior acúmulo de MS com o aumento da idade das plantas. Os teores de $\mathrm{N}$, em todas as idades de corte, ficaram abaixo do nível crítico proposto por Lemaire e Salette (1984), implicando em INN insuficiente para atender ao requerimento da gramínea por $\mathrm{N}$, pois a razão entre o teor de $\mathrm{N}$ na MS e o NCN foi inferior a 1,0. Para o fósforo, em todas as idades de corte, os percentuais ficaram acima do nível crítico interno deste nutriente, o qual foi estimado em $1,27 \mathrm{~g} / \mathrm{kg}$ (COSTA et al., 2004b). Já, para o potássio, os teores verificados nas plantas com até 28 dias de idade foram superiores ao nível crítico interno reportado por Costa et al. (2004a) para a gramínea $(16,10 \mathrm{~g} / \mathrm{kg})$.

Tabela 2. Teor de nitrogênio crítico $\left(\mathrm{N}_{\text {crítico }}\right)^{1}$, índice de nutrição nitrogenada (INN) $)^{2}$ e teores de nitrogênio, fósforo, cálcio, magnésio e potássio de Brachiaria humidicola cv. Tupi, em função da idade das plantas.

\begin{tabular}{cccccccc}
\hline $\begin{array}{c}\text { Idade } \\
(\text { dias })\end{array}$ & $\begin{array}{c}\mathrm{N}_{\text {crítico }} \\
(\mathrm{g} / \mathrm{kg})\end{array}$ & $\begin{array}{c}\mathrm{INN} \\
(\%)\end{array}$ & $\mathrm{N}$ & $\mathrm{P}$ & $\mathrm{Ca}$ & $\mathrm{Mg}$ & $\mathrm{K}$ \\
\hline 14 & 24,91 & 87,0 & $21,68 \mathrm{a}$ & $1,62 \mathrm{a}$ & $4,98 \mathrm{a}$ & $3,73 \mathrm{a}$ & $17,33 \mathrm{a}$ \\
21 & 21,43 & 94,1 & $20,16 \mathrm{a}$ & $1,58 \mathrm{ab}$ & $4,92 \mathrm{a}$ & $3,53 \mathrm{ab}$ & $16,98 \mathrm{a}$ \\
28 & 17,90 & 96,8 & $17,33 \mathrm{~b}$ & $1,54 \mathrm{~b}$ & $4,81 \mathrm{a}$ & $3,17 \mathrm{bc}$ & $16,54 \mathrm{a}$ \\
35 & 17,22 & 86,4 & $14,88 \mathrm{c}$ & $1,51 \mathrm{~b}$ & $4,77 \mathrm{a}$ & $2,89 \mathrm{c}$ & $15,22 \mathrm{~b}$ \\
42 & 16,91 & 70,5 & $11,93 \mathrm{~d}$ & $1,47 \mathrm{c}$ & $4,70 \mathrm{a}$ & $2,83 \mathrm{c}$ & $14,09 \mathrm{c}$ \\
\hline
\end{tabular}

- Médias seguidas de mesma letra não diferem entre si $(\mathrm{P}>0.05)$ pelo teste de Tukey

1. $\mathrm{N}_{\text {crítico }}=3,6 \cdot \mathrm{MS}^{(-0,34)}$

2. $\mathrm{INN}=$ Teor de $\mathrm{N} \div \mathrm{N}_{\text {crítico }}$ 
COSTA, N.L. et al. Produção de forragem, composição química e morfogênese de Brachiaria humidicola cv. Tupi em diferentes idades de corte. PUBVET, Londrina, V. 5, N. 8, Ed. 155, Art. 1044, 2011.

\section{Conclusões}

O aumento da idade das plantas resultou em maiores rendimentos de forragem e vigor de rebrota, contudo implicou em decréscimos significativos dos teores de nitrogênio, fósforo, magnésio e potássio, enquanto que os de cálcio não foram afetados. O tamanho médio de folhas e sua taxa de senescência foram diretamente proporcionais às idades das plantas, ocorrendo o inverso quanto à taxa de aparecimento de folhas, enquanto que a taxa de expansão foliar não foi afetada pela idade da planta. A idade de corte mais adequada para pastagens de $B$. humidcola cv. Tupi, visando a conciliar produção, vigor de rebrota e qualidade da forragem, situa-se entre 28 e 42 dias.

\section{Referências Bibliográficas}

CARRÈRE, P.; LOUAULT, F.; SOUSSANA, J.F. Tissue turnover within grass-clover mixed swards grazed by sheep: methodology for calculating growth, senescence and intake fluxes. Journal of Applied Ecology, v.34, p.333-348, 1997.

CHAPMAN, D; LEMAIRE, G. Morphogenetic and structural determinants of plant regrowth after defoliation. In: INTERNATIONAL GRASSLAND CONGRESS, 17., 1993, Palmerston North. Proceedings... Palmerston North: New Zealand Grassland Association, 1993. p.95104.

COSTA, N. de L.; GONÇALVES, C.A.; OLIVEIRA, M.A.S. et al. Rendimento de gramíneas forrageiras em Ariquemes-RO. Porto Velho: EMBRAPA-UEPAE Porto Velho, 1988. 4p. (Comunicado Técnico, 63).

COSTA, N. de L.; GONÇALVES, C.A.; TOWNSEND, C.R. et al. Rendimento, composição química e valor nutritivo da forragem. In: COSTA, N de L. (Ed.) Formação, manejo e recuperação de pastagens em Rondônia. Porto Velho: Embrapa Rondônia, 2004b. p.116-136.

COSTA, N. de L.; OLIVEIRA, J.R. da C. Evaluación agronómica de accesiones de Panicum maximum en Rondônia. Pasturas Tropicales, Cali, v.16, n.2, p.44-46, 1994.

COSTA, N. de L.; PAULINO, V.T.; RODRIGUES, A.N.A. et al. Calagem e adubação de pastagens. In: COSTA, $\mathrm{N}$ de L. (Ed.) Formação, manejo e recuperação de pastagens em Rondônia. Porto Velho: Embrapa Rondônia, 2004a. p.81-115.

COSTA, N. de L.; PAULINO, V.T.; TOWNSEND, C.R. Produção de forragem e composição química de Panicum maximum cv. Tanzânia em diferentes idades de corte. In: ENCONTRO DE PESQUISADORES DE RONDÔNIA, 3., 1997, Porto Velho. Anais... Porto Velho: UNIR, 1997, p.51.

COSTA, N. de L.; PAULINO, V.T.; MAGALHÃES, J.A. Produção de forragem e morfogênese de Brachiaria humidicola sob diferentes níveis de nitrogênio. In: REUNIÃO ANUAL DA 
COSTA, N.L. et al. Produção de forragem, composição química e morfogênese de Brachiaria humidicola cv. Tupi em diferentes idades de corte. PUBVET, Londrina, V. 5, N. 8, Ed. 155, Art. 1044, 2011.

SOCIEDADE BRASILEIRA DE ZOOTECNIA, 44., 2007, Jaboticabal. Anais... Jaboticabal: SBZ, 2007. 3p. (CD-ROM)

DIFANTE, G. dos S.; NASCIMENTO JÚNIOR, D.; SILVA, S.C. et al. Morfogênese do capimmarandu submetido a combinações de altura e intervalos entre cortes. In: REUNIÃO ANUAL DA SOCIEDADE BRASILEIRA DE ZOOTECNIA, 42., 2005, Goiânia. Anais... Goiânia: SBZ, 2005. 3p. (CD-ROM)

GOMIDE, C.A.M.; GOMIDE, J.A. Morfogênese de cultivares de Panicum maximum Jacq. Revista Brasileira de Zootecnia, Viçosa, v.29, n.2, p.341-348, 2000.

GOMIDE, J.A. Fisiologia do crescimento livre de plantas forrageiras. In: Pastagens: Fundamentos da Exploração Racional. Piracicaba: FEALQ. 1994. p.1-14.

GOMIDE, J.A. Morfogênese e análise de crescimento de gramíneas tropicais. In: SIMPÓSIO INTERNACIONAL SOBRE PRODUÇÃO ANIMAL EM PASTEJO, Viçosa, 1997. Anais... Viçosa: UFV, p.411-430, 1997.

GONÇALVES, A. de C. Características morfogênicas e padrões de desfolhação em pastos de capim-Marandu submetidos a regimes de lotação contínua. Piracicaba: ESALQ, 2002, 124p. (Dissertação de Mestrado).

GRANT, S.A.; BERTHARM, G.T.; TORVELL, L. Components of regrowth in grazed and cut Lolium perene swards. Grass and Forage Science, v.36, p.155-168, 1981.

HORST, G.L.; NELSON, C.J.; ASAY, K. H. Relationship of leaf elongation to forage yield of tall fescue genotypes. Crop Science, v.18, n.5, p.715-719, 1978.

LEMAIRE, G. Ecophysiological of grasslands: Dynamics aspects of forage plant population in grazed swards. In: INTERNATIONAL GRASSLAND CONGRESS, 19., 2001, São Paulo, Proceedings... São Paulo: ESALQ, 2001, p.29-37.

LEMAIRE, G.; AGNUSDEI, M. Leaf tissue turnover and efficiency of herbage utilization. In: LEMAIRE, G.; HODGSON, J.; MORAES, A. et al. (Eds). Grassland ecophysiology and grazing ecology. London: CAB International, 2000. p.265-288.

LEMAIRE, G.; GASTAL, F. N uptake and distribuition in plant canopies. In: LEMAIRE, G. (Ed.) Diagnosis of nitrogen status in crop. Heidelberg: Springer - Verlag, 1997. p. 3-43. 6

LEMAIRE, G.; GASTAL, F.; SALETTE, J. Analysis of the effect of $\mathrm{N}$ nutrition on dry matter yield of $a$ sward by reference to potential yield and optimum $N$ content. In: INTERNATIONAL GRASSLAND CONGRESS, 16., 1989, Nice, France. Proceedings... Versailles, France: Association Francaise pour la Production Fourragere, 1989. v.1, p.179180.

LEMAIRE, G; SALETTE, J. Relation entre dynamique de croissance et dymamique de prévèment d'azote pour un peuplement de graminées fourragéres. 1. Etude de l'effet du milieu. Agronomie, v.4, p.241-249, 1984

LEITE, G.G.; GOMES, A.C.; NETO, R.T. et al. Expansão e senescência de folhas de gramíneas nativas dos cerrados submetidas à queima. Pasturas Tropicales, Cali, v.20, n.3, p.16-21, 1998. 
COSTA, N.L. et al. Produção de forragem, composição química e morfogênese de Brachiaria humidicola cv. Tupi em diferentes idades de corte. PUBVET, Londrina, V. 5, N. 8, Ed. 155, Art. 1044, 2011.

NABINGER, C. Eficiência do uso de pastagens: disponibilidade e perdas de forragem. In: SIMPÓSIO SOBRE MANEJO DA PASTAGEM, 14., 1997, Piracicaba. Anais... Piracicaba: FEALQ, 1997. p.213-251.

ZARROUGH, K.M.; NELSON, C.J.; SLEPER, D.A. Interrelationships between rates of leaf appearance and titlering in selected tall fescue populations. Crop Science, v.24, p.565$569,1984$. 